\title{
Urban design against the background of biosphere and social processes
}

\author{
Zinaida Ivanova ${ }^{1, *}$ and Igor Pryadko \\ ${ }^{1}$ Moscow State University of Civil Engineering, Yaroslavskoe shosse, 26, Moscow, 129337, Russia
}

\begin{abstract}
In this article, the co-authors tackle the problem of the social sense and mission of the projects developed by urban planners and architects. The co-authors address the key issue of the present-day architectonics, that is, the ability and willingness of urban designers to give consideration to the environment, or the local landscape, to assure the harmonious co-existence of the biosphere and the needs of the society in Smart city. The co-authors compare the spatial organization principles of eastern and western cultures; they also track the patterns of their implementation in the present-day architectonics. The co-authors provide the findings of the public opinion pollabout the urban environment layout. Students of the Moscow State University of Civil Engineering (Russia) acted as the respondents. The co-authors employed the findings of the document analysis and the opinion poll to develop recommendations for architects and urban designers in respect of social and ecological needs of urban residents.
\end{abstract}

\section{Introduction}

The mission of this research is to analyze the efforts invested by contemporary urban designers and architects into development of the biosphere compatible and socially friendly urban environment. The co-authors believe that this issue is highly relevant, because the civilization has reached its growth limits, and from now on, any further social, political, demographic, migration, technological, or cultural processes will cause unpredictable and uncontrollable qualitative changes in the present-day society. There is a pressing need for the analysis of the processes which are underway in the present-day urban society, particularly, the analysis of their social and ecological constituents. No wonder that demographers, sociologists and urban designers attempt to tackle this problem; they do their best to understand the nature of the influence produced by these social processes on civil engineering and architecture and to find out the extent to which architecture can redirect the society's development vectors. Problems of biosphere compatible cities and architecture turn all the more relevant today. "Cities accommodate the source of the biosphere's degradation; human degradation comes into sharp focus there. That's why we need to initiate any improvements in the cities... Urban development must serve human

\footnotetext{
*Corresponding author: ivanovazi@mail.ru
} 
development." This viewpoint was expressed by V.A. Ilyichev, a Russian researcher and member of the Academy of Sciences [1].

The social sense of any activities performed by builders and architects, the influence produced by architecture on the worldview and behavior of urban residents constitute frequent subjects of research projects. The most ambitious statement of the problem of social essence of the urban designer's activity is available in the book written by Leo Hollis, a British urban specialist, entitled "Cities are good for you". The author believes that any efficiently organized space contributes to the feeling of comfort, safety, and abundance. The book, written by Leo Hollis, represents an attempt to offer new principles of design and restructuring in major cities, the principles which are capable of improving the social and economic vitality of cities and their residents [2]. J. Gehl, a Danish architect, also considers reasonable design as a means for the organization of social spaces and consolidation of social communities [3]. According to W. Rybczynski, the idea of comfort is as wifely change able notion; that's why new generations of architects and urban designers have to develop new concepts and implement new ideas in order to satisfy the needs of urban residents [4].V.L. Glazychev, a Russian art expert and architect, also believes that the main principle of architectural design consists in satisfaction of human needs [5].V.A. Ilyichev [1], K.V. Kiyanenko [6], M.B. Vilkovsky [7], and H. Delitz [8] have made the contributions into the development of urban design for the latter to be responsive to the social environment, on the one hand, and the biosphere, on the other hand.

Landscape urbanism, capable of serving the needs of urban residents/social groups in a megalopolis, is frequently discussed at science conferences; in particular, at the science and practice conference entitled "The comprehensive approach towards the humanization of the urban life", held on August 28-29, 2014, in Moscow by the Moscow City Architecture Committee; at the conference on "Urban environment. Reloading", held on the 8th of April, 2014, under the auspices of Expert media holding company, and at the annual Moscow urban forum. The most acute urban planning problems were discussed at the Moscow urban forum in 2014. At the roundtable discussion entitled "The megalopolis as the living environment. How can we preserve the ecological balance there?" the speakers discussed in what way advanced technologies had been efficiently employed to solve the environmental problems of major cities. The speakers also identified the factors of environmental quality reduction worldwide, discussed new trends and prospects for the environmentalization of urban development and demonstrated the most pronounced greening cases [9].

\section{Materials and Methods}

The mission of our research is to analyze the extent to which urban and architectural designs respond to social and biosphere problems. The co-authors have made an attempt to find out the degree of relevance of these problems from the standpoint of urban planners and architects, urban authorities and executives of professional communities. The coauthors also try to find out the extent to which social and ecological needs of urban residents are served in urban development plans. The co-authors will focus their attention on the most relevant problems of Russian cities and solve them in reliance on the positive experience accumulated by the European urban development practice. The co-authors employed the historic method and the document analysis to complete this section. However, the co-authors have to admit that social needs and high-quality urban environments are not on the list of the top priority objectives of practicing urban designers and planners.

In addition, the authors used the method of the opinion poll.

The opinion poll about contemporary urban design and architecture was conducted among the future civil engineers or present-day students of the Moscow State University of 
Civil Engineering (MGSU) in 2016. MGSU students are chosen as respondents because this university trains specialists capable of working efficiently in the context of new social and ecological challenges [10].

\section{Results}

The poll objective was to identify the attitude (acceptance/rejection) towards contemporary urban planning projects in terms of comfortable living. One hundred respondents, including freshmen, sophomores and junior students, participated in the poll. The poll findings were compared to the opinions expressed by the experts - the leading specialists in civil engineering and urban design. According to the poll findings, future civil engineers attach much significance to the appearance and visual comfort of their home city $(89 \%$ of the respondents). About $60 \%$ are not quite satisfied with the architectural planning solutions of the urban districts, while $15 \%$ of the respondents do not like the Moscow environment from the standpoint of its visual appeal. Mere $3 \%$ of the respondents take no interest in this problem. Only $31 \%$ of the respondents believe that urban comfort and appearance are interrelated, while $69 \%$ do not agree with this statement. Nonetheless, the respondents do not express any willingness to design the urban space themselves. Mere $37 \%$ of the respondents were eager to design the architectural space of their home city, district, street or yard.

The poll findings have proven that even those young men, who specialize in civil engineering, are not willing to design the urban space. In most cases, it develops spontaneously, under the influence of accidental factors. Besides, the degree of satisfaction with the urban architectural planning environment is also low.

In the experimental section, the co-authors earmark the binding need for the opinion polls to be conducted before the implementation of any urban planning projects: only if we are aware that urban residents express discontent due to the unavailability of something in a city, we can make plans to have it constructed in the future. Before any design process is initiated, instruments of sociology should be employed to analyze the problem, and the needs of potential consumers of buildings and structures, or urban residents, should be identified. Contemporary cities are complex structure due to the variety of subcultures that they accommodate: varied age, ethnic, confessional, and youth groups have varied needs and wants; therefore, their vision of this problem must be identified. Besides, there is a need to simulate the perception of an implemented project by the future residents of urban areas, and to project their approval or rejection. We know that not every architect knows how to apply his or her knowledge of sociology and its methodology. That's why he/she will need to approach sociologists specializing in architectural and urban sociology. A sociologist must have a profound knowledge of the subject matter and be proficient in architecture.

\section{Discussion}

\subsection{Socially oriented architectural and urban planning design}

Socially oriented urban design projects must meet the following interrelated challenges:

1) the needs of the society and local residents as the future users of implemented architectural design projects, and as those whose worldview will accommodate the architect's works;

2) the features of the biosphere or the local landscape and the adjustment of the model design to best suit the local terrain. 
Architects have always had to meet the challenges of this kind (let us remember the reconstruction of London by Christopher Wren, a brilliant British architect, after a devastating fire; for the first time in the history of London the reconstruction served the needs of ordinary Londoners). This trend is not accidental: socially oriented urban planning is turning into one of the imperatives of our era. Therefore, we cannot help agreeing with the conclusion made by the contemporary researcher: "Successful cities reflect the needs and ambitions of the society that they accommodate..." [11]. Contemporary urban development strategies serve to intensify the social potential of cities, improve their comfort and set the stage for the expanded reproduction of urban residents.

Today these plans are evident; they arise no disputes. However, these apparent urban planning solutions haven't been feasible at all times, because urban planners and architects had to follow the demands of their customers, including individuals and the state. Any demands are limited by the financial capacity, available budget proceeds and investments to be made by the state. Besides, the architect's activities are restricted by the rules and procedures, specified in Construction Norms and Rules (Russian Standard "SNIPs"), the Urban Planning Code and other regulatory acts.

For example, any investor and contractor prefer high-rise buildings. Their logic is simple: the more stories the foundation accommodates, the higher the revenues. In their turn, architects realize the viciousness of this pattern, as the higher the building, the higher the impact of such factors as the pressure produced on the soil and foundation, and the higher the exposure of residents, occupying top stories, to psychological tension. Residents of top floors find it problematic to dispose of their litter; solar exposure regulations are violated there. Nonetheless, architects have toe the line. Developers never agree to reduce the number of stories. Therefore, low-storey construction projects have not turned into a trend yet, however, they have generated "new environmental features", according to F. Kudryavtsev, Head of the Laboratory of Urban Planning Research of the Moscow Institute of Architecture [11]. Infill development has not been stopped, although it worsens the urban landscape and causes social problems. The majority of the respondents - students of civil engineering -agreed that any infill development corrupted the landscape of urban areas and made urban districts less comfortable $(68 \%)$.

Another expert, M. Atoyants, an architect, appeals for the statutory regulation of commercial construction. He is sure that "the unavailability of any effective legal norms causes the emergence of terrifying homogenous landscapes filled with standardized residential houses." Now the Russian language has naturalized a set expression that reads as "wild development". Indeed, any development turns wild, whenever and wherever it is not limited by the laws. Nevertheless, now the Moscow region is limiting the number of stories, according to A. Vorontsov, Director of Department of Architecture and Urban Planning of the Moscow region [11].

\section{2 Architectural and urban planning design focused on the biosphere}

Architects and urban planners must serve the needs of the biosphere along with any social wants. According to the projections, made by the UN, by $205075 \%$ of the global population will have lived in cities and towns. Therefore, the exposure to the anthropogenic load there will go up multi-fold. Today almost each party, including investors, architects, and developers, realize the need to reduce the exposure to anthropogenic loads and to make sure that the natural comfort is in place, and there is enough space and fresh air on the sites occupied by construction facilities [12]. They do realize these needs, but they fail to serve them in every case.

According to E. Batynkova, Deputy General Director in Charge of Realty, Garden Blocks Open Joint Stock Company, so-called "stone bags", or standardized residential 
houses, take the place of cozy green spots due to the strong willingness of developers to maximize their revenues, on the one hand, and due to the fact that neither developers, nor architects know how to design green landscapes in the urban environment"'[13].As a result, buildings are not resident friendly; therefore, they reduce the feeling of comfort and damage the natural environment. The majority of our respondents rejected "stone bags", and the overwhelming majority of our respondents $(62 \%)$ were not satisfied with the exterior of their native urban districts.

Let us get back to the problem of spatial organization through the construction of architectural ensembles responsive to factors of local terrain and climate. The biosphere compatibility of landscapes and urban/rural areas requires the embodiment of mental ideas developed by varied ethnicities. "Nature has an immaterial spirit, some "genius", perceived by the man through archetypes and images, implemented in architectural forms and grasped through the skyline of a city, visible from afar. The dwelling of an ancient person - a hut, a cabin, or a tent imitated the shape of a mountain or a cave, thus, depicting a shelter. Then the shape turned more complex. As the time progressed, tents transformed into domes and gambrel houses of Ukrainian Art Nouveau; however, the pattern that they embodied remained the same. This pattern is archetypical; it is based on natural forms"[14].

For example, the archetypes of the collective unconscious, maintained by the residents of the Far East, convert into their meditative attitude towards the environment; therefore, they add sacral meaning to things and phenomena. Thus, the whole architectural environment can become an extension of the natural environment. According to $\mathrm{K}$. Kurokawa, a Japanese architect, "connections with nature, simplicity, traditional ideas represent everything that we need to design modern structures"[15].

The core features of traditional Chinese and Japanese architecture included natural simplicity, perfect forms, harmonious balance between buildings and natural landscapes. Zen monasteries were built on woody mountain slopes to get visually dissolved in the landscape. They were perceived as the continuation of slopes, steep coasts and impassable forests full of dragons... The buildings were highly appreciated, if they served as a foil to the beauty, neutrality and uniqueness of natural landscapes. Traditional Japanese dwellings strived for simplicity, transformable design and minimalism. M. Shunmyo, a Japanese landscape designer, is convinced that gardens surrounding Buddhist temples "are the treasury of the Japanese landscape culture" [16].Indeed, in the ancient times, monks designed gardens to attain serenity and to identify the essence of the Zen [17]. Japanese biosphere compatible architecture is called "the architecture, which is kind to the environment". Japanese designers demonstrate their surprising attitude towards specific urban contexts, nature, people, construction traditions, principles of responsible use of new technologies and materials in their work. In Japanese, the expression that means "Japanese architecture" contains a special speech pattern, depicting the culture of relations between man and natural environment.

Unfortunately, huge heap of rubbish, contaminated urban areas of the industrial East, changing qualitative environmental parameters, nearly permanent shrouds of smog over highways and streets, full of vehicles, fail to comply with the traditional Eastern image of architecture. However Eastern Architects Still cherish the traditional value of nature and the willingness to have harmonious relationship established between nature and architectural ensembles. Even today contemporary architects implement breath-taking projects by "borrowing" motives from nature. This "borrow-from-nature" technique is fundamental for bionics, a highly popular concept underlying contemporary biotech architecture. For example, specialists from Vincent Callebaut Architectures studio borrowed an idea from lithospheres formations for their new project. Their construction facility got a highsounding name of "Asian mounds". This impressive architectural facility will be constructed in Shenzhen, Chin [18]. 
Nevertheless, we cannot claim that architecture was opposed to forces of nature in western countries. There, human habitat was adjusted to nature both in terms of its exterior, internal composition, and application of construction technologies and materials. In the western world, architecture was also a reflection of the worldview generated in the collective consciousness of the ethnicity. Material and spiritual cultures, maintained by any ethnicity, can evolve, if driven by the natural environment. The socio-cultural environment strives for the biosphere compatibility. This statement is proven by the findings of our poll. $72 \%$ of the respondents preferred to have a park near their homes, while mere $28 \%$ chose a supermarket to be constructed nearby.

The extensive period of industrial architecture neglected any links with nature and filled cities and towns with "stone bag"-like buildings. Now the works created by domestic and foreign architects tend to have stronger environmental links.

For example, unlike the projects, developed by Le Corbusier and other modernists, whose works are full of direct lines and regular angles, O. Niemeyer's works are full of curves and bent forms. He overcame the direct lines of constructivism by employing natural curves and curvilinear planes. O. Niemeyer's projects depict the natural shapes of Brazilian landscapes: expressive and curvilinear mountain chains, clouds and rivers, as well as delicate contours of a female body [19].

Architects themselves hold ongoing discussions of interaction between architecture and nature. N. Foster, a contemporary architect, remarks that attention should be drawn not to such separate notions as the landscape or climate, but to the synthesis between flora, climate, and landscape. N. Foster, same as his predecessor V.G. Shukhov, employed a system-based approach to his work. "We have returned the museum to a historic tradition of marrying architecture and landscape... Our approach to design is similarly guided by a unique sense of place - by the national and the local context; by research and analysis of the climate, culture, and the needs of many different users. The potential to harness nature to provide foliage and shelter, to ventilate or bring light into a building, is equally profound - by working in harmony with the environment, design can help to protect and conserve energy and natural resources" [20]. Therefore, we can conclude that simplicity, environmental friendliness and expediency constitute the main principles for Norman Foster's architectural projects (following K. Kurokawa). Foster's projects can be labeled as biosphere compatible.

\section{Conclusions}

This research proves that architecture is the type of creative activity which is highly responsive to any processes underway both in the natural environment and in the society. Its willingness to respond to societal needs and to meet biosphere's challenges is a pressing need of our century. Now architectural design focuses on global warming, droughts, and frequent floods. According to L. Hollis, humankind is on the verge of disaster, while the city is the point of support, without which there will be no future for us [1]. Development of urban designs with account for the future climatic and demographic changes, anticipated in every country of the world, is highly valuable for the creation of biosphere compatible cities. A combination of traditions, ethnic and mental features, social needs and those of the biosphere, technologically novel architectural and urban planning solutions should be the core trend in the activities of any contemporary urban planner and architect.

This study was conducted with the support of the project "Erasmus + Jean Monnet" Intercultural Europe: Urban Planning Based on the Principles of Social Integration" (IEUP), funded by the European Commission. The conclusions and opinions presented in this document reflect the viewpoint of the authors only, and the Commission will not bear responsibility for any use of the information contained therein. 


\section{References}

1. V. A. Ilyichev, Biosphere Compatibility: Technologies for Introduction of Innovations. Cities That Develop Humans (Librokom, Moscow,2011).

2. L. Hollis, Cities are Good for You. The Genius of the Metropolis (Bloomsbury Press, New York, 2013).

3. J. Gehl, Cities for people (Island Press, Washington, 2010).

4. W. Rybczynski, Makeshift Metropolis: Ideas About Cities (Scribner, 2010).

5. V. L. Glazychev, Architecture, 2 (21) (1978)

6. K. V. Kiyanenko, Architectural Newsletter 3(108) (2009)

7. M. B. Vilkovsky, Sociology of the Architecture («Russian Avant-garde» Heritage Preservation Foundation, Moscow, 2010).

8. H. Delitz, Sociological researches 10,113-121 (2008)

9. http://go.mail.ru/search?gp=822323\&fr=chxtn12.0.11

10. Z. I. Ivanova, O. V. Yudenkova, A.D. Ishkov, E.A. Shnyrenkov, International Education Studies 8(5), 232-239 (2015).

11. A. Vikhrova, Urban New 4, 2-3 (2014).

12. E. Romanova, MATEC Web of Conferences, 73, 07010 (2016)

13. URL: http://www.sadkvartal.ru/project/smi/191.html

14. URL: http://www.rusnauka.com/PNR_2006/Stroitelstvo/1_martyshova201.s..doc.htm

15. URL:http://bibliofond.ru/view.aspx?id=668398.

16. S. Mostovoy, Urban New 1, 4 (2015)

17. The Earth and climatic changes in the new world. The world of cities, 2, 5 (2011)

18. URL:http://kisakuku.ru/news/?view=10424_Proekt_bashen_iz_kamney_\%C2\%ABAz iatskie_kurganyi $\% \mathrm{C} 2 \% \mathrm{BB}$.

19. URL:http://www.artic.edu/exhibition/oscar-niemeyer.

20. PURL: http://www.archdaily.com/?p=466544.

21. M.G. Leontev, MATEC Web of Conferences 73, 07005 (2016) 